\title{
EVALUATION OF RELEASE RATIOS OF Rhantus elevatus SHARP (COLEOPTERA, DYTISCIDAE) AS A PROMISING BIOLOGICAL CONTROL AGENT AGAINST Culex pipiens L. (DIPTERA, CULICIDAE) UNDER LABORATORY CONDITIONS.
}

\author{
Abdel-Salam, A. H.; M. E. Ragab and A. R. Ahmed \\ Economic Entomology Department, Faculty of Agriculture, Mansoura \\ University, Mansoura 35516, Egypt.
}

\begin{abstract}
This study was outlined to declare the effect of release of Rhantus elevatus (larvae and adults) at different predator: prey ratios ( $P$ : $p)$ to control the larvae and pupae of mosquito, Culex pipiens under laboratory conditions. Effective control of second mosquito larvae was gained after one day from introducing the first instar larvae of predator when the P:p ratio was 1:25 or 1:50. After releasing the first instar larvae, a completely reduction in the third mosquito larvae was $100 \%$ after four days at $P: p$ ratios $1: 100,1: 125$ and $1: 150$. Completely decreased of fourth instar mosquito larvae was occurred after two days at $P: p$ ratios $1: 25$ and 1:50, respectively. After one day of releasing the first predator larvae against pupal mosquito stage, the reduction rate was $21.00,12.50,8.33,5.00,5.60$ and $4.00 \%$ at $P: p$ ratios $1: 25,1: 50,1: 75$, $1: 100,1: 125$ and 1:150, respectively. Release of first instar predator larvae against mixed mosquito larvae recorded one hundred reduction percentage after one day at
\end{abstract} $P: p$ ratio $1: 25$.

A complete control after one day was achieved at $P: p$ ratios 1:25 and 1:50 when releasing of second instar larvae of predator against the second instar larvae of mosquito. Releasing the second instar larvae of $R$. elevatus against third instar larvae of $C$. pipiens showed a complete control after one day at $P: p$ ratio $1: 25$. When using the second instar larvae of predator to control the fourth instar larvae of mosquito, the results indicated that an effective control of mosquito larvae was observed after four days at $P: p$ ratio 1:150. Second instar larvae of predator showed a complete reduction in pupal mosquito stage at $P: p$ ratios $1: 25$ and 1:50 after one and two days respectively. After two days, the reduction rate was $41.50,51.40,62.50,86.00$ and $100.00 \%$ at $P: p$ ratios $1: 150,1: 125,1: 100,1: 75$ and $1: 50$, respectively. One hundred reduction rate was recorded after one day of releasing second instar predator larvae against mixed mosquito larvae at $P: p$ ratios $1: 25$ and 1:50.

When the third instar larvae of predator was released against the second mosquito larvae, a complete reduction was occurred after one day at $P: p$ ratios $1: 25$, $1: 50,1: 75$ and 1:100. A completely reduction of third instar mosquito larvae was achieved after one day at P:p ratios 1:25 and 1:50. A control percentage of fourth instar larvae of mosquito was 80.00 and $59.50 \%$ after one day at $P$ :p ratios $1: 75$ and 1:100, respectively. Third instar larvae of predator showed a complete reduction against pupal stage at $P: p$ ratios 1:25 and 1:50 after one day. A completely control of mixed mosquito larvae was achieved after one day at $P: p$ ratios 1:25, 1:50, 1:75 and $1: 100$.

Results of releasing adults with the predator: prey ratio of 1:100 showed that the predator adults were successfully eliminating the third instar of mosquito larvae after two days from the release. The number of mosquito larvae decreased by 60.25 , 37.33, 27.75, 23.70 and $19.75 \%$ for $1: 100,1: 150,1: 200,1: 250$ and 1:300 ratio, respectively. When releasing the predator adults against the fourth instar mosquito larvae, the reduction rate was $65.67,49.87,41.10$ and $33.34 \%$ at $P: p$ ratios $1: 150$, 
$1: 200,1: 250$ and 1:300, respectively after two days. During pupal stage of mosquito, the reduction percentage was $29.75,20.50,13.86,13.30$ and $10.25 \%$ after one day of releasing pedator adults at $P: p$ ratios 1:100, 1:150, 1:200, 1:250 and 1:300, respectively. When releasing $R$. elevatus adults to control mixed instar larvae of $C$. pipiens, a completely control was observed after two, three, four and five days at $P: p$ ratios 1:100, 1:150, 1:200 and 1:250, respectively.

According to regression analysis between $\mathrm{P}: \mathrm{p}$ ratios of $R$ elevatus (larvae and adults) and reduction percentage of larvae and pupae of mosquito, there were negatively high relationship of predator, which means that the reduction rate was increased with lower $P$ : $p$ ratios and vice versa.

Keywords: Rhantus elevatus, predator: prey ratios, Culex pipiens, release.

\section{INTRODUCTION}

Mosquitoes are the most prominent of numerous species of blood sucking arthropods that annoy man and other warm-blooded animals. Their attacks on farm animals can cause loss of weight and decrease milk production. Some mosquitoes are capable of transmitting disease organisms that cause malaria, lymphatic filariasis, yellow fever, and dengue to man, encephalitis to man and horses, and heartworm to dogs (Kline, 2006).

The emergence of pesticide and drug resistant mosquitoes, coupled with a clearer appreciation of the long-term detrimental effects of powerful chemicals to non pest insects and concern about accumulation of pesticides in the food chain and environment, has high lighted the need to quickly develop an alternative. A promising alternative is biological control (Porter et al., 1993).

Several investigators have studied the natural and biological control of mosquito larvae by predators (e.g. Bence, 1988; Blaustein \& Byard, 1993; Takagi et al., 1995), as do some invertebrates, especially notonectids and odonates (e.g. Hazelrigg, 1974; Blaustein et al., 1995; Blaustein, 1998; Stav et al., 2000). Nonetheless, there is a little evidence that populations of mosquito larvae in the field are actually limited by predation (Lundkvist et al., 2003). A variety of aquatic insects in the orders Odonata, Hemiptera, Coleoptera, and Diptera are will known to prey upon mosquito larvae. (Collins and Washino, 1985). In Egypt, some authors studied the biological control agents of mosquitoes, (Tawfik et al., 1986 and 1990; Abdel-Aal et al., 1998; Abdel-Aal, 2000).

The dytiscid beetles like Rhantus sikkimensis, $R$. consputus and Colymbates paykulli, Hydroporus sp, and llybus ater are known to prey upon mosquito immatures. In rice fields and temporary pools, larvae and adults of dytiscid beetles are dominant predators and have a strong impact in regulating mosquito populations. Considering the predatory nature of the dytiscid beetles, an assessment of the larvae of Acilius sulcatus was made as a bio-control agent against the filarial vector Culex quinquefasciatus Say. both under laboratory and field conditions. (Chandra et al., 2008).

However, scanty attention has been paid on the impact of $R$. elevatus as a bio-control agent against $C$. pipiens. Therefore, the present work has been designed to compare the effect of released larvae and adults of $R$. elevatus, and to evaluate the optimal predator: prey ratio against larvae and pupal stages of $C$. pipiens under laboratory conditions. 


\section{MATERIALS AND METHODS}

\section{1- Rearing C. pipiens.}

Rearing of $C$. pipiens in the laboratory was carried out by the same method previously described by Singh et al., 1972, Shams Eldin, 1981 and Abou Bakr, 1984. Egg rafts of mosquito were taken from the pools by plastic strainer and transferred to the laboratory and carefully placed in groups by means of a fine camel-hair bruch in pots (40 cm in diameter), 1/2 filled of tap water that kept overnight to get rid of chlorine residues. After hatching, larvae were provided with a fine mixture of ground dried bread and dried brewers yeast with a ratio of $2: 1$, respectively. This mixture was always kept dry in the refrigerator. Immediately be used the mixture was suspended in a little amount of water and then added to the rearing pans by means of a dropper to reach the bottom of each pan so as to avoid skum formation. The amount of provided food was increased with the progress of larval growth. Water was changed twice a weak. Larvae were kept in these pans until pupation. During this period, plastic strainers with different meshes and different sizes were used either when changing water or to segregate different larval instars. However, mosquito larvae showed a uniformal rate of growth under natural conditions and overcrowding in the rearing pans were avoided as much as possible. Mosquito pupae were separated by using plastic dropper and kept in plastic pots to transfer in wood cages covered with muslin cloth from all sides with a canvas sleeve at one of its faces, the pupae left until the adults emerged. The adult cages were provided with ovipositions pots and a Petridish lined with a sponge saturated with sugar solution (10\%) as a food for males and supplementary food for females. Sugar solution was changed daily after washing up both the sponge and the Petri-dishes. Mosquito females were allowed to have a blood meal from pigeon twice a weak. The first meal was available 48 hours after emergence. After the females get the blood meal, it laid the eggs directly on the water surface in ovipositions pots which $1 / 5$ filled of tap water.

\section{2- Rearing $R$. elevatus.}

The predator adults were sampled with metallic strainer from natural pools and transferred to the laboratory of Economic Entomology Department, Faculty of Agriculture, Mansoura University. Adults were putting in big glass pot contains water from the natural breeding sites and contains of water plant, Elodea canadensis. The eggs laid by each female of predator were removed daily and monitored until hatching. The hatched larvae were reared individually on the larvae of $C$. pipiens. The first, second and third larval instars of $R$. elevtus were released against single larvae $\left(2^{\text {nd }}, 3^{\text {rd }}\right.$ and $4^{\text {th }}$ instars or mixed larvae) and pupal stage of mosquito at the following predator: prey ratios: $1: 25,1: 50,1: 75,1: 100,1: 125$ and 1:150. while, adults of $R$. elevtus were released at the following predator: prey ratios: 1:100, 1:150, 1:200, 1:250 and 1:300. Four replicates were used at different predator: prey ratios in pots $(40 \mathrm{~cm}$ in diameter). The number of preys was carefully counted every day for six days to evaluate the success of release. 
Data analysis:

Simple linear regression between predator: prey ratio and reduction percentage was run (Costat, 2004).

\section{RESULTS AND DISSCUSSION}

Releasing $R$. elevatus larvae and adults against larvae and pupae of $C$. pipiens.

1. Larvae.

A. First instar:

An effective control of second instar larvae of mosquito was achieved after one day from release of the first instar predator larvae with the predator: prey ratio of 1:25 (Table 1). It was observed that the number of the second instar larvae of mosquito at this ratio remained zero for a period of five days after release of the predator larvae. When the predator: prey ratio was 1:50, the reduction percentage was 57.00 and $100.00 \%$ after one and two days from the releasing the predator larvae, then the mosquito numbers remained zero after four days from release. Whereas, at 1:125 and 1:150, the second mosquito larvae reduced by 19.6 and $16.00 \%$ after one day, 43.60 and $35.50 \%$ after two days, and 76.40 and $62.50 \%$ after three days from release of the predator larvae. From the above mentioned results, the effective control of second mosquito larvae was gained after one day from introducing the larvae of the predator when the P:p ratio was 1:25 or 1:50, while at higher ratios (1:125 and 1:150), the first larvae of predator decreased mosquito larvae after four days from release.

When releasing the first predator larvae against the third instar larvae of $C$. pipiens, a completely reduction in mosquito larvae was occurred after two days at $P: p$ ratios $1: 25$ and 1:50. Meanwhile, the reduction rate was $28.00,70.33$ and $100.00 \%$ at $P: p$ ratio $1: 75$. The reduction in the third mosquito larvae was $100.00 \%$ after four days at $P: p$ ratios 1:100, 1:125 and 1:150, respectively.

Results in Table (1) showed that completely decreased of the fourth instar mosquito larvae was occurred after two days at P:p ratios 1:25 and $1: 50$, respectively. But at P:p ratio 1:75, the reduction rate was $28.70,73.70$ and $100.00 \%$ after one, two and three days, respectively. At P:p ratio 1:100, the reduction rate was $18.25,47.50,75.75$ and $100.00 \%$ after one, two, three and four days, respectively. Meanwhile, after four days, the reduction rate was 90.20 and $76.80 \%$ at P:p ratios $1: 125$ and $1: 150$, after that the mosquito adults emerged from pupae.

After one day of releasing the first predator larvae against pupal mosquito stage, the reduction rate was $21.00,12.50,8.33,5.00,5.60$ and $4.00 \%$ at $P: p$ ratios $1: 25,1: 50,1: 75,1: 100,1: 125$ and $1: 150$, respectively. However, after two days, the reduction rate was 44.00, 23.00, 15.33, 11.25, 10.20 and $8.17 \%$ at the same previous P:p ratios. In the third day, the mosquito adults were emerged from pupae.

Effect of first instar predator larvae against mixed mosquito larvae also showed in Table (1). One hundred reduction percentage was recorded 
after one day at P:p ratio $1: 25$. The reduction was $100.00 \%$ after two days at 1:50 and 1:75 P:p ratios. But at P:p ratios 1:100, the reduction percentage was $30.50,81.50$ and $100.00 \%$ after one, two and three days. In addition, at P:p ratios $1: 125$ and 1:150, a completely reduction after three days was recorded.

Table 1: Reduction percentage of larvae and pupae of $C$. pipiens after release of the first instar larvae of $R$. elevatus at different predator: prey ratios under laboratory conditions.

\begin{tabular}{|l|c|c|c|c|c|c|c|}
\hline $\begin{array}{c}\text { Larval } \\
\text { instars and } \\
\text { pupal stage } \\
\text { of mosquito }\end{array}$ & $\begin{array}{c}\text { Days } \\
\text { after } \\
\text { release }\end{array}$ & $\mathbf{1 : 2 5}$ & $\mathbf{1 : 5 0}$ & $\mathbf{1 : 7 5}$ & $\mathbf{1 : 1 0 0}$ & $\mathbf{1 : 1 2 5}$ & $\mathbf{1 : 1 5 0}$ \\
\hline Second instar & 1 & 100.00 & 57.00 & 35.67 & 27.00 & 19.60 & 16.00 \\
& 2 & - & 100.00 & 77.00 & 57.00 & 43.60 & 35.50 \\
& 3 & - & - & 100.00 & 100.00 & 76.40 & 62.50 \\
& 5 & - & - & - & - & 100.00 & 100.00 \\
\hline Third instaryyyyyyyy & 1 & 88.00 & 46.00 & 28.00 & 19.25 & 15.20 & 12.83 \\
& 2 & 100.00 & 100.00 & 70.33 & 48.00 & 38.80 & 33.33 \\
& 3 & - & - & 100.00 & 88.00 & 71.20 & 60.83 \\
& 4 & - & - & - & 100.00 & 100.00 & 100.00 \\
& 5 & - & - & - & - & - & - \\
\hline Fourth instar & 1 & 79.00 & 38.50 & 28.70 & 18.25 & 15.40 & 13.33 \\
& 2 & 100.00 & 100.00 & 73.70 & 47.50 & 39.20 & 34.83 \\
& 3 & - & - & 100.00 & 75.75 & 62.80 & 54.97 \\
& 4 & - & - & - & 100.00 & 90.20 & 76.80 \\
& 5 & - & - & - & - & Adult & Adult \\
& 1 & 100.00 & 56.50 & 41.00 & 30.50 & 24.20 & 21.50 \\
& 2 & - & 100.00 & 100.00 & 81.50 & 66.40 & 58.33 \\
& 3 & - & - & - & 100.00 & 100.00 & 100.00 \\
& 4 & - & - & - & - & - & - \\
& 5 & - & - & - & - & - & - \\
\hline Mixed instars & 1 & 21.00 & 12.50 & 08.33 & 05.00 & 05.60 & 04.00 \\
& 2 & 44.00 & 23.00 & 15.33 & 11.25 & 10.20 & 08.17 \\
& 3 & Adult & Adult & Adult & Adult & Adutt & Adult \\
& 4 & emergence & emergence & emergence & emergence & emergence & emergence \\
& 5 & - & - & - & - & - & - \\
& & - & - & - & - & - & - \\
\hline
\end{tabular}

The regression equations between predator: prey ratios of the first instar larvae of $R$. elevatus (as independent variable $\mathrm{X}$ ) and reduction percentages of larvae and pupae of $C$. pipiens (as dependent variable $Y$ ) were derived (Figures. 1, 2, 3, 4, and 5). These equations indicated that there was a highly negative relationship between $P: p$ ratios and reduction rates which mean that the reduction rate was increased with lower P: $p$ ratios and vice versa. These results generally agree with those of Manivannan and Madani (2005) who reported that first instar Cybister lateralimarginalis (Coleoptera: Dytiscidae) larvae consumed a mean number of 34 fourth instar larvae, 21.3 third instar larvae, 19.3 second instar larvae, 12.3 first instar larvae of Culex. Chandra et al. (2008) noted that a single larva of Acilius sulcatus (Coleoptera: Dytiscidae) consumed an average 34 fourth instar larvae of Culex quinquefasciatus Say in a $24 \mathrm{~h}$ period. 
Abdel-Salam, A. H. et al.

f1-2 
J. Agric. Sci. Mansoura Univ., 34 (1), January, 2009

f3-4-5 


\section{B. Second instar:}

A control after one day was achieved when released the second instar larvae of $R$. elevatus against the second instar larvae of mosquito at P:p ratios $1: 25$ and 1:50. While, the reduction rate was $100.00 \%$ after two days at P:p ratios $1: 75,1: 100,1: 125$ and 150 . After one day, the reduction rate at $P: p$ ratios $1: 75,1: 100,1: 125$ and $1: 150$ was $73.70,65.00,42.20$ and $32.00 \%$, respectively (Table 2 ).

Releasing the second instar larvae of $R$. elevatus against the third instar larvae of $C$. pipiens showed a complete control after one day at P:p ratio 1:25. But after two days, an effective control was gained at P:p ratios $1: 50,1: 75$ and $1: 100$ and after three days at $P: p$ ratios $1: 125$ and 1:150. After one day, the reduction rate was $81.00,54.67,41.00,32.20$ and $26.00 \%$ at P:p ratios $1: 50,1: 75,1: 100,1: 125$ and $1: 150$, respectively. But after two days, the reduction percentage was 79.00 and $64.67 \%$, respectively.

When using the second instar larvae of predator to control the fourth instar larvae of mosquito, the results indicated that a complete control of mosquito larvae was observed after four days at $P: p$ ratio $1: 150$. At $P: p$ ratio $1: 150$, the reduction rate was $24.00,54.17,92.67$ and $100.00 \%$ after one, two, three and four days, respectively. At P:p ratio 1:125, a control percentage of fourth mosquito larvae was $31.00,69.80$ and $100.00 \%$ after one, two and three days, respectively. In addition, a complete reduction was observed after three days at P:p ratio 1:100. At P:p ratios 1:50 and 1:75, the reduction rate after one day was 79.00 and $51.33 \%$. A complete reduction in mosquito larvae at these ratios was observed after two days. At P:p ratio $1: 25$, all mosquito larvae were consumed by the second instar larvae of predator.

Second instar larvae of predator showed a complete reduction in pupal mosquito stage at P:p ratios 1:25 and 1:50 after one and two days respectively. After two days, the reduction rate was 41.50, 51.40, 62.50, 86.00 and $100.00 \%$ at P:p ratios 1:150, 1:125, 1:100, 1:75 and 1:50, respectively. In the third day, the mosquito adults were emerged from pupae.

Data presented in Table (2) illustrate the effect of the second instar larvae against mixed instars of mosquito larvae. One hundred reduction rate was recorded after one day at P:p ratios 1:25 and 1:50. This reduction was $100.00 \%$ after two days at 1:75 and 1:100 P:p ratios. Whereas, at P:p ratio $1: 125$, the reduction was $44.80,93.40$ and $100.00 \%$ after one, two and three days. At P:p ratio 1:150, a completely reduction was recorded after three days. After one day, the reduction rate was $88.33,59.90,44.80$ and $39.33 \%$ at P:p ratios 1:75, 1:100, 1:125 and 1:150, respectively. But after two days, the reduction rate was 93.40 and $83.33 \%$ at P:p ratios 1:125 and 1:150, respectively.

Based on simple linear regression between $P: p$ ratios of second instar larvae of $R$. elevatus and reduction percentage of mosquito, there were negatively strong relationship after one, two and three days. (Figures $6,7,8$, 9, and 10). These results are similar with Manivannan and Madani (2005) who found that second instar larvae of Cybister lateralimarginalis fed on a mean of 31 fourth instar larvae, 13.9 third instar larvae, 28.8 second instar larvae, 22.2 first instar larvae of Culex. 
J. Agric. Sci. Mansoura Univ., 34 (1), January, 2009

6-7-8 
Table 2: Reduction percentage of larvae and pupae of $C$. pipiens after release of the second instar larvae of $R$. elevatus at different predator: prey ratios under laboratory conditions.

\begin{tabular}{|c|c|c|c|c|c|c|c|}
\hline \multirow{3}{*}{\begin{tabular}{|c|} 
Larval \\
instars and \\
pupal stage \\
of mosquito \\
Second instar \\
\end{tabular}} & \multirow{2}{*}{$\begin{array}{l}\text { Days } \\
\text { after } \\
\text { release }\end{array}$} & \multicolumn{6}{|c|}{ P:p ratios } \\
\hline & & $1: 25$ & $1: 50$ & 1:75 & 1:100 & 1:125 & 1:150 \\
\hline & $\begin{array}{l}1 \\
2 \\
3 \\
4 \\
5\end{array}$ & $\begin{array}{l}100.00 \\
=\end{array}$ & $\begin{array}{l}100.00 \\
= \\
=\end{array}$ & $\begin{array}{c}73.70 \\
100.00 \\
= \\
=\end{array}$ & $\begin{array}{c}65.00 \\
100.00 \\
- \\
-\end{array}$ & $\begin{array}{c}42.20 \\
100.00 \\
= \\
-\end{array}$ & $\begin{array}{c}32.00 \\
100.00 \\
= \\
=\end{array}$ \\
\hline Third instar & $\begin{array}{l}1 \\
2 \\
3 \\
4\end{array}$ & $\frac{100.00}{-}$ & $\begin{array}{c}81.00 \\
100.00 \\
- \\
-\end{array}$ & $\begin{array}{c}54.67 \\
100.00 \\
=\end{array}$ & $\begin{array}{c}41.00 \\
100.00 \\
\text { - }\end{array}$ & $\begin{array}{c}32.20 \\
79.00 \\
100.00 \\
-\end{array}$ & $\begin{array}{c}26.00 \\
64.67 \\
100.00 \\
-\end{array}$ \\
\hline Fourth instar & $\begin{array}{l}1 \\
2 \\
3 \\
4 \\
5\end{array}$ & $\begin{array}{l}100.00 \\
= \\
=\end{array}$ & $\begin{array}{c}79.00 \\
100.00 \\
- \\
-\end{array}$ & $\begin{array}{c}51.33 \\
100.00 \\
= \\
=\end{array}$ & $\begin{array}{c}40.00 \\
85.50 \\
100.00 \\
-\end{array}$ & $\begin{array}{c}31.00 \\
69.80 \\
100.00 \\
-\end{array}$ & $\begin{array}{c}24.00 \\
54.17 \\
92.67 \\
100.00\end{array}$ \\
\hline Mixed instars & $\begin{array}{l}1 \\
2 \\
3 \\
4 \\
5\end{array}$ & $\begin{array}{l}100.00 \\
= \\
=\end{array}$ & $\begin{array}{l}100.00 \\
= \\
-\end{array}$ & $\begin{array}{c}88.33 \\
100.00 \\
= \\
-\end{array}$ & $\begin{array}{c}59.50 \\
100.00 \\
= \\
-\end{array}$ & $\begin{array}{c}44.80 \\
93.40 \\
100.00 \\
-\end{array}$ & $\begin{array}{c}39.33 \\
83.33 \\
100.00 \\
-\end{array}$ \\
\hline Pupal stage & $\begin{array}{l}1 \\
2 \\
3\end{array}$ & $\begin{array}{l}100.00 \\
= \\
=\end{array}$ & $\begin{array}{c}64.50 \\
100.00 \\
- \\
-\end{array}$ & $\begin{array}{c}39.00 \\
86.00 \\
\text { Adult } \\
\text { emergence }\end{array}$ & $\begin{array}{l}29.25 \\
62.50 \\
\text { Adult } \\
\text { emergence }\end{array}$ & $\begin{array}{c}24.80 \\
51.40 \\
\text { Adult } \\
\text { emergence }\end{array}$ & $\begin{array}{c}1 \overline{9.00} \\
41.50 \\
\text { Adult } \\
\text { emergence }\end{array}$ \\
\hline & $\begin{array}{l}4 \\
5\end{array}$ & 二 & 二 & - & 二 & 二 & 二 \\
\hline
\end{tabular}

\section{Third instar:}

When releasing the third instar larvae of tested predator against the second mosquito larvae, a complete reduction was recorded after one day at P:p ratios 1:25, 1:50, 1:75 and 1:100. Meanwhile, at P:p ratios 1:125 and $1: 50$, a complete reduction of second mosquito larvae was occurred after two days. A control rate was 89.40 and $100.00 \%$ after one day. At P:p ratio 1:150 a reduction rate was $75.83 \%$ after one day as shown in Table (3).

A completely reduction of the third instar mosquito larvae was achieved after one day at P:p ratios $1: 25$ and 1:50, but at P:p ratios 1:75, $1: 100,1: 125$ and 1:150, the reduction percentage after one day was 93.33, $70.75,55.80$ and $47.83 \%$, respectively. At P:p ratios $1: 75,1: 100$ and $1: 125$, a complete reduction was recorded after two days, but at P:p ratio 1:150, a complete reduction was achieved after three days.

Data in Table (3) indicate that a completely decreased of fourth instar mosquito larvae was recorded after one day at P:p ratios 1:25 and 1:50, but at P:p ratio $1: 75$ and 1:100, a completely reduction rate was achieved after two days. At P:p ratios 1:125 and 1:150, a completely reduction was recorded after three days. A control percentage was 80.00 and $59.50 \%$ after one day at $P: p$ ratios $1: 75$ and $1: 100$, respectively. At P:p ratio $1: 125$, the mortality rate was $49.20,96.40 \%$ after one and two days, respectively. The reduction 
rate was 39.00 and $82.70 \%$ at P:p ratio $1: 150$ after one and two days, respectively.

Table 3: Reduction percentage of larvae and pupae of $C$. pipiens after release of the third instar larvae of $R$. elevatus at different predator: prey ratios under laboratory conditions.

\begin{tabular}{|c|c|c|c|c|c|c|c|}
\hline \multirow{3}{*}{\begin{tabular}{|c|}
$\begin{array}{c}\text { Larval } \\
\text { instars and } \\
\text { pupal stage } \\
\text { of mosquito }\end{array}$ \\
Second instar \\
\end{tabular}} & \multirow{2}{*}{$\begin{array}{c}\text { Days } \\
\text { after } \\
\text { release }\end{array}$} & \multicolumn{6}{|c|}{ P:p ratios } \\
\hline & & $1: 25$ & $1: 50$ & $1: 75$ & 1:100 & 1:125 & 1:150 \\
\hline & $\begin{array}{l}1 \\
2 \\
3 \\
4 \\
5\end{array}$ & $\begin{array}{l}100.00 \\
= \\
=\end{array}$ & $\begin{array}{l}100.00 \\
= \\
=\end{array}$ & $\begin{array}{c}100.00 \\
E \\
=\end{array}$ & $\begin{array}{c}100.00 \\
= \\
=\end{array}$ & $\begin{array}{c}89.40 \\
100.00 \\
= \\
=\end{array}$ & $\begin{array}{c}75.83 \\
100.00 \\
= \\
=\end{array}$ \\
\hline Third instar & $\begin{array}{l}1 \\
2 \\
3 \\
4 \\
5\end{array}$ & $\begin{array}{l}100.00 \\
=\end{array}$ & $\begin{array}{l}100.00 \\
= \\
=\end{array}$ & $\begin{array}{c}93.33 \\
100.00 \\
- \\
-\end{array}$ & $\begin{array}{c}70.75 \\
100.00 \\
= \\
-\end{array}$ & $\begin{array}{c}55.80 \\
100.00 \\
=\end{array}$ & $\begin{array}{c}47.83 \\
92.99 \\
100.00 \\
-\end{array}$ \\
\hline Fourth instar & $\begin{array}{l}1 \\
2 \\
3 \\
4 \\
5\end{array}$ & $\begin{array}{l}100.00 \\
= \\
=\end{array}$ & $\begin{array}{l}100.00 \\
= \\
=\end{array}$ & $\begin{array}{c}80.00 \\
100.00 \\
- \\
-\end{array}$ & $\begin{array}{c}59.50 \\
100.00 \\
- \\
-\end{array}$ & $\begin{array}{c}49.20 \\
96.40 \\
100.00 \\
-\end{array}$ & $\begin{array}{l}39.00 \\
82.70 \\
100.00 \\
- \\
-\end{array}$ \\
\hline Mixed instars & $\begin{array}{l}1 \\
2 \\
3 \\
4 \\
5\end{array}$ & $\begin{array}{l}100.00 \\
= \\
=\end{array}$ & $\begin{array}{l}100.00 \\
= \\
=\end{array}$ & $\begin{array}{l}100.00 \\
E \\
=\end{array}$ & $\begin{array}{c}100.00 \\
= \\
=\end{array}$ & $\begin{array}{c}85.40 \\
100.00 \\
= \\
=\end{array}$ & $\begin{array}{c}71.83 \\
100.00 \\
= \\
=\end{array}$ \\
\hline Pupal stage & $\begin{array}{l}1 \\
2 \\
3 \\
4 \\
5 \\
5\end{array}$ & $\begin{array}{c}100.00 \\
=\end{array}$ & $\begin{array}{c}100.00 \\
= \\
=\end{array}$ & $\begin{array}{c}74.67 \\
100.00 \\
- \\
- \\
-\end{array}$ & $\begin{array}{c}62.25 \\
100.00 \\
- \\
= \\
-\end{array}$ & $\begin{array}{c}45.60 \\
87.60 \\
\text { Adult } \\
\text { emergence } \\
= \\
-\end{array}$ & $\begin{array}{c}36.83 \\
69.33 \\
\text { Adult } \\
\text { emergence } \\
\underline{-}\end{array}$ \\
\hline
\end{tabular}

The third instar larvae of considered predator showed a complete reduction against pupal stage of mosquito at P:p ratios 1:25, 1:50 after one day. In addition, one hundred reduction percentage was recorded after two days at P:p ratios $1: 75$ and 1:100. The reduction percentage was 74.67, $62.25,45.60$ and $36.83 \%$ after one day at P:p ratios 1:75, 1:100, 1:125 and $1: 150$, respectively. After two days, the reduction percentage was 87.60 and $69.33 \%$ at P:p ratios $1: 125$ and $1: 150$, respectively. In the third day, the mosquito adults were emerged from pupae.

A completely control of mixed mosquito larvae was achieved after one day at $P: p$ ratios $1: 25,1: 50,1: 75$ and $1: 100$. After one day, the reduction percentage was 85.40 and $71.83 \%$ at $P: p$ ratios $1: 125$ and 1:150, respectively. A completely reduction also was achieved after two days during the last two P:p ratios.

The regression equations between predator: prey ratios of third instar larvae of $R$. elevatus (as independent variable $\mathrm{X}$ ) and reduction percentages of larvae and pupae of $C$. pipiens (as dependent variable $Y$ ) were derived (Figures. 11, 12, 13, 14, and 15). 
Abdel-Salam, A. H. et al.

9-10-11-12

580 
J. Agric. Sci. Mansoura Univ., 34 (1), January, 2009

13-14-15-16

581 
These equations indicated that there was a highly negative relationship between $P: p$ ratios and reduction rates which mean that the reduction rate was increased with lower $P: p$ ratios and vice versa. Similar trend with our results was obtained by Ree and Lee (1983) who found that a mong Coleopterous predators, late-instar larvae of Cybister japonicus Sharp preyed a daily average of 46.6 fourth instar Culex larvae and Laccophilus larvae consumed 118.9 mosquito larvae daily. It is concluded that the two dytiscid species are the most effective predators and would regulate populations of $C$. $p$. pallens to a much greater extent than any other associated predators. In addition, Manivannan and Madani (2005) reported that third instar Cybister lateralimarginalis larvae consumed a mean number of 36.6 fourth instar larvae, 19.5 third instar larvae, 22.1 second instar larvae, 13.9 first instar larvae of Culex.

\section{Adults:}

A completely reduction was recorded after two days at 1:100 P:p ratio, three days at 1:150 P:p ratio, four days at 1:200 P:p ratio, five days at 1:250 P:p ratio and after six days at 1:300 P:p ratio. After one day, the reduction percentage of mosquito larvae was $69.00,47.50,33.50,26.90$ and $23.33 \%$ at $P: p$ ratios $1: 100,1: 150,1: 200,1: 250$ and $1: 300$, respectively. After two days, the reduction percentage was $90.50,63.13,50.30$ and 44.49 at $P: p$ ratios $1: 150,1: 200,1: 250$ and 1:300, respectively. The reduction percentage was 89.50, 71.30 and 62.49 at P:p ratios 1:200, 1:250 and 1:300, respectively. The reduction percentage was 89.20 and 76.57 at P:p ratios $1: 250$ and 1:300, respectively. After five days, a reduction percentage was 90.30 at 1:300 P:p ratio (Table 4). Results of releasing adults with the predator: prey ratio of $1: 100$ showed that the predator adults were successfully eliminating the third instar of mosquito larvae after two days from the release. The number of mosquito larvae decreased by $60.25,37.33$, $27.75,23.70$ and $19.75 \%$ for $1: 100,1: 150,1: 200,1: 250$ and $1: 300$ ratio, respectively. It was noticed that the number of mosquito larvae remained zero for a period of five days after the release. At the predator: prey ratio of 1:150, the reduction percentage of mosquito larvae was $79.99 \%$ after two days. Whereas, at the higher ratios (1:250 and 1:300), the reduction percentage was 47.40 and $38.50,68.50$ and $55.67,88.00$ and $71.17,100.00$ and $85.92 \%$ after two, three, four and five days from the release, respectively.

When releasing the predator adults against the fourth instar larvae of mosquito, a completely reduction was recorded after two and four days at P:p ratios $1: 100$ and 1:150, respectively. After two days, the reduction rate was 65.67, 49.87, 41.10 and $33.34 \%$ at P:p ratios 1:150, 1:200, 1:250 and 1:300, respectively. In addition, the reduction rate after the third day was 92.67, 65.76, 52.70 and $43.01 \%$ at P:p ratios 1:150, 1:200, 1:250 and 1:300, respectively. After the fourth day from releasing, the reduction rate was $82.875,64.40$ and $53.01 \%$ at $P: p$ ratios $1: 200,1: 250$ and 1:300, respectively. The best control of mosquito larvae was achieved by using the lower predator: prey ratios (1:100 and 1:150) after two and four days from adults release.

During pupal stage of mosquito, the reduction percentage was 29.75 , $20.50,13.86,13.30$ and $10.25 \%$ after one day at $P: p$ ratios 1:100, 1:150, 
1:200, 1:250 and 1:300, respectively. However, after two days, a control percentage recorded $65.539 .50,30.36,26.70$ and $21.75 \%$ at P:p ratios $1: 100,1: 150,1: 200,1: 250$ and 1:300, respectively.

Table 4: Reduction percentage of larvae and pupae of $C$. pipiens after release of adults of $R$. elevatus at different predator: prey ratios under laboratory conditions.

\begin{tabular}{|c|c|c|c|c|c|c|}
\hline \multirow{2}{*}{$\begin{array}{c}\text { Larval } \\
\text { instars and } \\
\text { pupal stage } \\
\text { of mosquito }\end{array}$} & \multirow{2}{*}{$\begin{array}{l}\text { Days } \\
\text { after } \\
\text { release }\end{array}$} & \multicolumn{5}{|c|}{ P:p ratios } \\
\hline & & 1:100 & 1:150 & 1:200 & $1: 250$ & 1:300 \\
\hline Second instar & $\begin{array}{l}1 \\
2 \\
3 \\
4 \\
5 \\
6\end{array}$ & $\begin{array}{c}69.00 \\
100.00 \\
- \\
- \\
-\end{array}$ & $\begin{array}{c}47.50 \\
90.50 \\
100.00 \\
- \\
- \\
-\end{array}$ & $\begin{array}{c}33.50 \\
63.13 \\
89.50 \\
100.00 \\
- \\
-\end{array}$ & $\begin{array}{c}26.90 \\
50.30 \\
71.30 \\
89.20 \\
100.00 \\
-\end{array}$ & $\begin{array}{l}33 \\
49 \\
49 \\
57 \\
23 \\
00\end{array}$ \\
\hline Third instar & $\begin{array}{l}1 \\
2 \\
3 \\
4 \\
5 \\
6\end{array}$ & $\begin{array}{c}60.25 \\
100.00 \\
= \\
= \\
-\end{array}$ & $\begin{array}{c}37.33 \\
79.99 \\
100.00 \\
- \\
-\end{array}$ & $\begin{array}{c}27.75 \\
60.88 \\
86.38 \\
100.00 \\
- \\
-\end{array}$ & $\begin{array}{c}23.70 \\
47.40 \\
68.50 \\
88.00 \\
100.00 \\
-\end{array}$ & $\begin{array}{c}19.75 \\
38.5 \\
55.67 \\
71.17 \\
85.92 \\
\text { Adult } \\
\text { emergence }\end{array}$ \\
\hline Fourth & $\begin{array}{l}1 \\
2 \\
3 \\
4 \\
5 \\
\\
6\end{array}$ & $\begin{array}{c}49.50 \\
100.00 \\
= \\
-\end{array}$ & $\begin{array}{c}33.00 \\
65.67 \\
92.67 \\
100.00 \\
-\end{array}$ & $\begin{array}{c}24.75 \\
49.87 \\
65.76 \\
82.875 \\
\text { Adult } \\
\text { emergence }\end{array}$ & \begin{tabular}{|c|}
20.10 \\
41.10 \\
52.70 \\
64.40 \\
Adult \\
emergence
\end{tabular} & $\begin{array}{r}16.92 \\
33.34 \\
43.01 \\
53.01 \\
\text { Adult } \\
\text { emergence }\end{array}$ \\
\hline Mixed instars & $\begin{array}{l}1 \\
2 \\
3 \\
4 \\
5 \\
6\end{array}$ & $\begin{array}{c}49.00 \\
100.00 \\
- \\
- \\
-\end{array}$ & $\begin{array}{c}33.67 \\
69.17 \\
100.00 \\
- \\
-\end{array}$ & $\begin{array}{c}25.88 \\
51.75 \\
76.50 \\
100.00 \\
- \\
-\end{array}$ & $\begin{array}{c}20.90 \\
41.40 \\
60.80 \\
81.80 \\
100.00 \\
-\end{array}$ & \begin{tabular}{|c|}
17.17 \\
34.25 \\
51.75 \\
70.00 \\
87.42 \\
Adult \\
emergence
\end{tabular} \\
\hline Pupal stage & $\begin{array}{l}1 \\
2 \\
3 \\
\\
4 \\
5 \\
6\end{array}$ & $\begin{array}{c}29.75 \\
65.50 \\
\text { Adult } \\
\text { emergence } \\
\text { - } \\
-\end{array}$ & $\begin{array}{c}20.50 \\
39.50 \\
\text { Adult } \\
\text { emergence } \\
- \\
-\end{array}$ & $\begin{array}{c}13.86 \\
30.36 \\
\text { Adult } \\
\text { emergence } \\
\text { - } \\
\end{array}$ & $\begin{array}{c}13.30 \\
26.70 \\
\text { Adult } \\
\text { emergence } \\
- \\
-\end{array}$ & $\begin{array}{c}10.25 \\
21.75 \\
\text { Adult } \\
\text { emergence } \\
- \\
-\end{array}$ \\
\hline
\end{tabular}

When releasing $R$. elevatus adults to control mixed instar larvae of $C$. pipiens, a completely control was observed after two, three, four and five days at P:p ratios 1:100, 1:150, 1:200 and 1:250, respectively. Whereas, at P:p ratio $1: 300$, the reduction rate was $87.42 \%$ after five days from introducing the predator adults (Table 4). Similar results were obtained by Dubitskii et al. (1975) who noted the control of culicine species in the laboratory experiments (included Aedes caspius (Pall.), Culex modestus Fic., C. pipiens L. and Anopheles maculipennis $\mathrm{Mg}$ ) with water-beetles (Coleoptera, Dytiscidae). 
Abdel-Salam, A. H. et al.

17-18 
J. Agric. Sci. Mansoura Univ., 34 (1), January, 2009

$19-20$

585 
Tests were made with six species of Dytiscidae, of which three (Rhantus pulverosus (Steph.), Graphoderus cinereus (L.) and Colymbetes semenovi (Jakovlev)) live in lowland areas and the remainder (Agabus dichrous Sharp (Gaurodytes dichrous), A. basalis (G. basalis) (Gebl.) and A. bipustulatus (L.) (G. bipustulatus). The data showed that in a field experiment in which water-beetles were introduced at the rate of $25 / \mathrm{m}^{2}$ into a pool two $\mathrm{m}^{2}$ in area where the density of mosquito larvae was $2560 / \mathrm{m}^{2}$, the density fell to 435 individuals $/ \mathrm{m}^{2}$ after $24 \mathrm{~h}$. Whereas in a control pool in the same period the density of the larval population increased from $1986 / \mathrm{m}^{2}$ to $2592 / \mathrm{m}^{2}$. All the dytiscids tested readily attacked mosquito larvae and are promising agents of control. Aditya et al. (2006) demonstrated the rate of predation of fourth instar Culex quinquefasciatus larvae by Rhantus sikkimensis ranged between 21.56 and 86.89 larvae per day, depending on the prey and predator densities. The predatory impact $(\mathrm{PI})$ value remained between 18.67 and 35.33 larvae/day depending on prey densities, while the clearance rate ranged between 2.21 and 2.23 larvae litres/day/predator. The predator $R$. sikkimensis can consume a good number of mosquito larvae. It can be assumed that these predator play an important role in larval population regulation of mosquitoes.

Based on simple linear regression between $\mathrm{P}: \mathrm{p}$ ratios of $R$. elevatus adults and reduction percentage of the mosquitoes, there were negatively strong relationship after one, two, three, four and five days. (Figures 16, 17, 18, 19, and 20).

\section{REFERENCES}

Abdel-Aal, A.A. 2000. Laboratory observations on the efficiency of some natural enemies of culicine mosquito larvae in Assiut Egypt. Assiut Veterinary Medical Journal. 43(86): 350-36.

Abdel-Aal, A.A., N.F. Hamad, S.A. Okasha, and E.A.A. Shaalan. 1998. Studies on the biological control and ecology of mosquitoes in Aswan Governorate: 2. Ecological studies of mosquito larvae. Assiut Veterinary Medical Journal. 39 (77): 17-35.

Abou Bakr, H.E. 1984. Studies on certain biological control agents of mosquitoes in Egypt. Ph.D Thesis, Fac.Agric., Cairo Univ. 243pp.

Aditya, G., A. Anirban, and G.K. Saha. 2006. Predatory activity of Rhantus sikkimensis and larvae of Toxorhynchites splendens on mosquito larvae in Darjeeling, India . Journal of Vector Borne Diseases. 43(2): 66-72.

Bence, J.R. 1988. Indirect effects and biological control of mosquitoes by mosquitofish. Journal of Applied Ecology 25: 505-521.

Blaustein, L. 1998. Influence of the predatory backswimmer, Notonecta maculata, on invertebrate community structure. Ecological Entomology 23: 246-252.

Blaustein, L. and R. Byard. 1993. Predation by a cyprinodontid fish, Aphanius mento, on Culex pipiens: effects of alternative prey and vegetation. Journal of the American Mosquito Control Association 9: 356-358. 
Blaustein, L., B.P. Kotler, and D. Ward. 1995. Direct and indirect effects of a predatory backswimmer (Notonecta maculata) on community structure of desert temporary pools. Ecological Entomology 20, 311-318.

Chandra, G., S.K Mandal, A.K. Ghosh, D. Das, S.S. Banerjee and S. Chakraborty. 2008. Biocontrol of larval mosquitoes by Acilius sulcatus (Coleoptera: Dytiscidae). In press.

Collins, F.H. and R.K. Washino. 1985. Insect predators. In: Chapman, H.C. (ed.) Biological control of mosquitoes. Bull. Am. Mosq. Contr. Assoc. 6: 25-42.

Costat Software. 2004. Microcomputer program analysis, version 4.20 CoHort Software, Berkely, CA, USA.

Dubitskii, A.M., R.T. Akhmetbekova, and V.V. Nazarov. 1975. Water-beetles (Coleoptera, Dytiscidae) in mosquito control. Izvestiya Akademii Nauk Kazakhstan, USSR, Biol. 5: 47-52.

Hazelrigg, J. 1974. Notonecta unifasciata as predators of mosquito larvae in simulated field habitats. Proceedings of the California Mosquito Control Association 42: 60-65.

Kline, D.L. 2006. 'Mosquito Biology', Encyclopedia of Pest Management, 1(1): 1-3.

Lundkvist, E., J. Landin, M. Jackson, and C. Svensson. 2003. Diving beetles (Dytiscidae) as predators of mosquito larvae (Culicidae) in field experiments and in laboratory tests of prey preference. Bull. Entomol. Research. 93(3): 219-226.

Manivannan, D. and J.I. Madani. 2005. Prey preference in the larval instars of Cybister lateralimarginalis (Coleoptera: Dytiscidae). J. Ecobiology. 17(1): 11-16.

Porter, A.G., E.W. Davidson, and J.W. liu1. 1993. Mosquitocidal toxins of Bacilli and their genetic manipulation for fffective biological control of mosquitoes. Microbiological Reviews. 57(4): 838-861.

Ree, H.I. and W.J. Lee. 1983. Laboratory studies on predation efficacy of some Odonata nymphs and Coleoptera larvae against mosquito larvae. Korean J. Entomol. 13(2): 31-38.

Shams EIDean, M.M. 1981. Utilization of the nematode, Romanomermis culicivorax in the biological control of some mosquito species. M.Sc. thesis, Fac.Agric., Cairo Univ.

Singh, K.R.P., R.S. Patterson, G.C. LaBrecque, and R.K. Razdan. 1972. Mass rearing of Culex fatigans. WHO/VBC/72.386, 26 pp.

Stav, G., L. Blaustein, and Y. Margalit. 2000. Influence of nymphal Anax imperator (Odonata: Aeshnidae) on oviposition by the mosquito Culiceta longiareolata (Diptera: Culicidae) and community structure in temporary pools. J. Vect. Ecology 25: 190-202.

Takagi, M., W. Pohan, H. Hasibuan, W. Panjaitan, and T. Suzuki. 1995. Evaluation of shading of fish farming ponds as a larval control measure against Anopheles sundaicus Rodenwaldt (Diptera: Culicidae). Southeast Asian Journal of Tropical Medicine and Public Health 26: 748-753. 


\section{Abdel-Salam, A. H. et al.}

Tawfik, M.F.S., F.M. El-Borollosy, I.A. Hemeida and E. Agamy. 1990. The biology of the water boatman Sigara lateralis (Leach) (Hemiptera: Corixidae).Bull.Soc.Ent.Egypt. 69: 217-227.

Tawfik, M.F.S., M.M. El-Husseini, and H. Abou-Bakr. 1986. Ecological observations on aquatic insects attacking mosquitoes in Egypt. Bull.Soc.Ent.Egypt. 66: 117-126.

تقييم نسب الإطلاق المختلفة لمفترس R. elevatus كعامل مكافحة حيويـة فعـال ضد بعوض الكيولكس Culex pipiens.

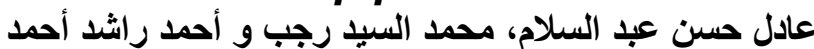
قسم الحشرات الإقتصاديةــ كلية الزراعة. جامعة المنصورة

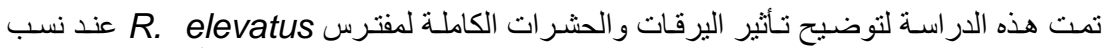

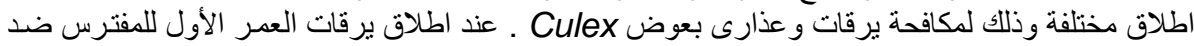

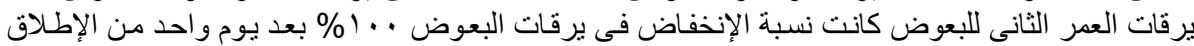

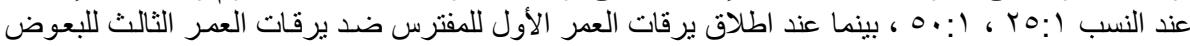

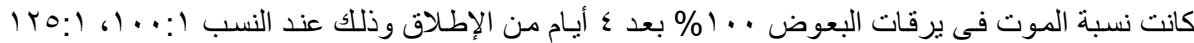

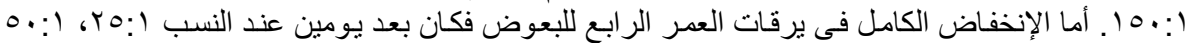

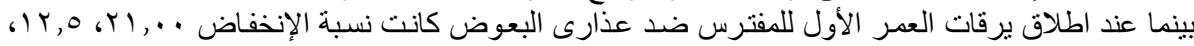

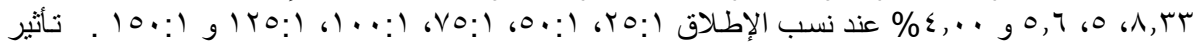

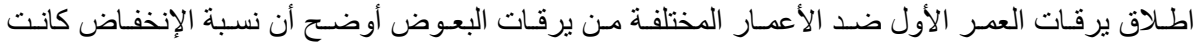

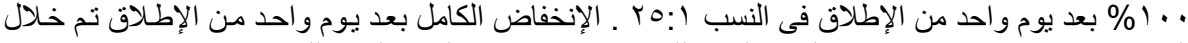

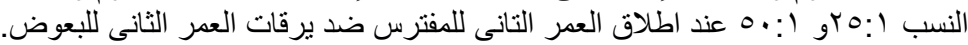

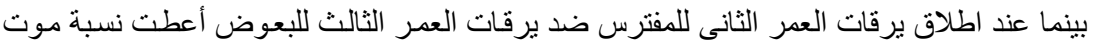

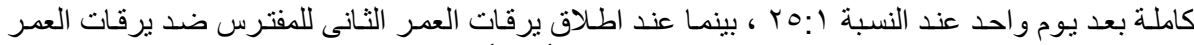

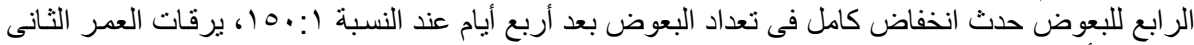

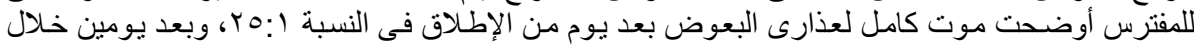

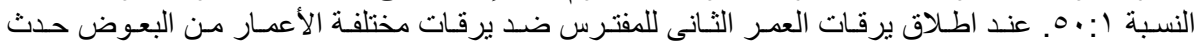

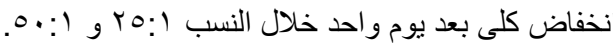

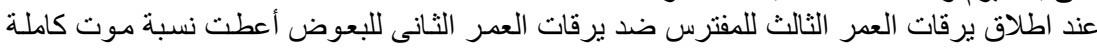

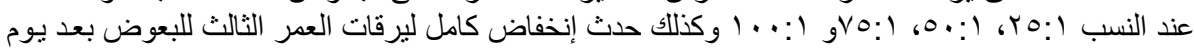

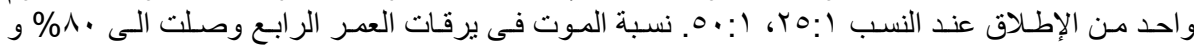

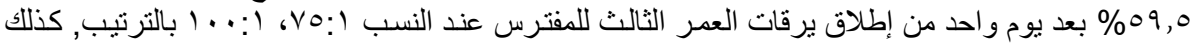

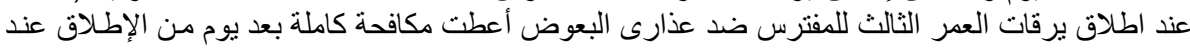

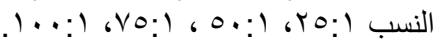

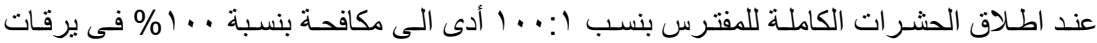

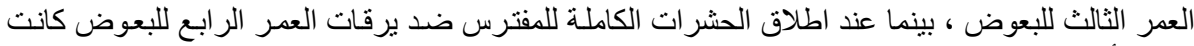

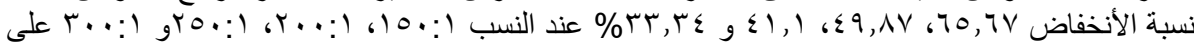

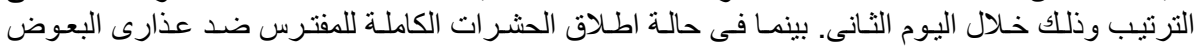

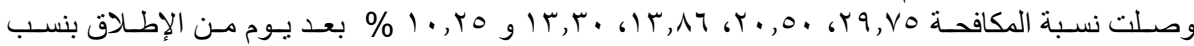

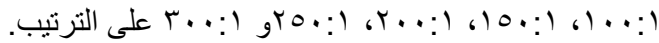

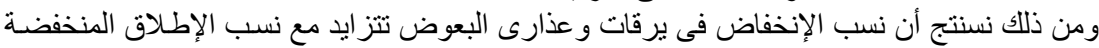

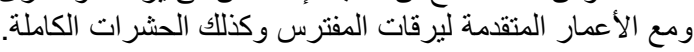

